\title{
Analisis praktik pengungkapan informasi intellectual capital dalam laporan tahunan perusahaan telekomunikasi di Indonesia
}

\author{
Ihyaul Ulum MD. \\ Universitas Muhammadiyah Malang, Jawa Timur \\ Jl. Raya Tlogomas 246 Malang \\ Email:mas_ulum@yahoo.com
}

\begin{abstract}
The aim of this study is to describe the intellectual capital disclosure practices by Indonesian telecommunication industry. Content analysis was used to analyze the annual report for two years, 2007 and 2008. This research used Guthrie and Petty's scheme of intellectual capital components. In this scheme, IC was categorized to 3 groups; internal structures (organizational capital: 11 ${ }^{\text {th }}$ items); external structures (customer/relational capital: $9^{\text {th }}$ items); and employee competence (human capital: $8^{\text {th }}$ items).

The result shows that percentage of IC disclosure by Indonesian telecommunication industry was high relatively, compare with the other overseas results. In 2007, there was some attributes that not disclosed yet by company, it was 'patent', 'copyright', dan 'trademark'. But in 2008, all of IC attributes were disclosed by companies, even not of all companies.

There was no company that discloses all of $28^{\text {th }}$ component of IC at their annual report. The maximum number of attribute that disclosed by company was 24 .
\end{abstract}

Keywords: intellectual capital disclosure, telecommunication industry, content analysis

\section{pendahuluan}

Praktik pengungkapan informasi intellectual capital(IC) di dalam laporan tahunan perusahaan telah menjadi tema yang menarik banyak peneliti di berbagai negara (lihat misalnya: Williams, 2001; Brennan, 2001; April et al., 2003; dan Bozzolon et al., 2003). Tema ini menjadi menarik karena IC diyakini sebagai faktor penggerak dan pencipta nilai perusahaan (value driver \& creation). Beberapa penelitian telah menunjukkan bahwa IC berkontribusi signifikan terhadap kinerja perusahaan (lihat: Ulum, 2008a,b; 2009; Chen et al., 2005; dan Tan et al., 2007).

Penelitian mengenai pengungkapan indikator IC cenderung lebih fokus pada value relevance dari indikator IC yang lebih spesifik, seperti biaya penelitian dan pengembangan atau bahkan terkait dengan bagaimana aktiva tidak berwujud bisa dikapitalisasikan. Canibano et al. (1999) me-review sejumlah penelitian dimana relevansi nilai dari elemen-elemen lain dari IC (seperti: biaya penelitian dan pengembangan, iklan, paten, merek, kepuasan pelanggan, dan sumberdaya manusia) diteliti.

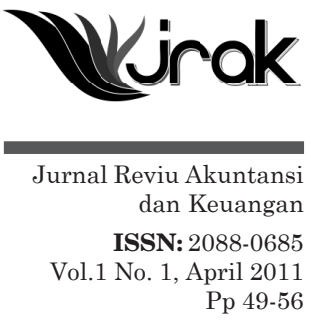


Analisis

Praktik

Pengungkapan

Informasi...

Meskipun masih terbatas, studi mengenai pengungkapan IC dalam beberapa tahun terakhir telah dilakukan di Australia, Austria, Inggris, Swedia, Belanda, Perancis, Irlandia, Kanada, Spanyol, Italy, Afrika Selatan, Hongkong, Malaysia, dan Indonesia. Laporan tahunan dipilih sebagai sumber data, karena mudah diperoleh, isi laporan tersebut telah diperiksa oeh perusahaan, dan laporannya juga terdistribusi secara luas pada publik (Campbell, 2000). Sampel perusahaan yang terdaftar sangat bervariasi, mulai dari perusahaan terbesar hingga perusahaan pada industri tertentu, tapi berjumlah tidak lebih dari 31 perusahaan, dengan demikian analisis statistiknya sangat terbatas.

Sejauh ini, penelitian-penelitian tentang pengungkapan IC untuk konteks Indonesia masih cukup terbatas. Diantara sedikit penelitian tersebut menguji faktor pemicu (anteseden) pengungkapan (Ariestyowati et al., 2009) dan dampak (consequencies) pengungkapan tersebut (Aprilima et al., 2009). Sementara penelitian yang fokus pada perusahaan telekomunikasi belum banyak ditemukan. Perusahaan telekomunikasi menjadi 'ikon' industri yang penting dalam kajian tentang IC (bersama dengan industri perbankan dan bioteknologi) karena tipologi bisnis dan kapasitas karyawannya yang berbeda dengan industri lainnya. Artikel ini berusaha memotret praktek pengungkapan IC oleh perusahaan telekomunikasi di Indonesia.

\section{Metode}

Penelitian ini merupakan penelitian eksploratif, yakni penelitian yang dimaksudkan untuk mengeksplorasi tipologi pengungkapan IC dalam laporan tahunan perusahaan publik di Indonesia dengan menggunakan pendekatan analisis isi (content analysis). Sampel yang digunakan adalah perusahaan-perusahaan di sektor telekomunikasi yang terdaftar hingga akhir tahun 2008 dan memublikasikan laporan tahunannya pada website resmi perusahaan dan/atau website BEI.

\section{Unit Analisis}

Unit analisis dalam penelitian ini adalah Intellectual Capital Disclosure (ICD). Kategori/komponen IC yang diadopsi dalam penelitian ini adalah skema yang digunakan oleh Guthrie and Petty (2000). Dalam skema ini, IC dikategorikan dalam dalam 3 kelompok: internal structures (organisational capital: 11 item); external structures (customer/relational capital: 9 item); dan employee competence (human capital: 6 item).

\section{Teknik Analisis Data}

Tujuan penelitian ini adalah untuk mengidentifikasi dan menyusun tipologi pengungkapan IC di dalam laporan tahunan perusahaan. Untuk mencapai tujuan ini, maka metode analisis yang digunakan adalah analisis isi (content analysis).

Analisis isi adalah suatu teknik yang sistematik untuk menganalisis makna pesan dan cara mengungkapkan pesan. Langkah yang dilakukan pada analisis isi dalam penelitian ini menggunakan interactive model dari Miles dan Huberman (Miles \& Huberman, 1994). Model ini mengandung 4 komponen yang saling berkaitan, yaitu (1) pengumpulan data, (2) penyederhanaan atau reduksi data, (3) penyajian data, (4) penarikan dan pengujian atau verifikasi simpulan.

Content analysis merupakan instrumen yang paling tepat untuk menginvestigasi praktik pengungkapan IC oleh perusahaan (Guthrie et al., 2006). Pendekatan ini telah digunakan oleh para peneliti untuk mengidentifikasi hal yang sama dengan penelitian ini (lihat misalnya: Guthrie and Petty, 2000; Bozzolan et al., 2003; dan Brennan, 2001). 
Dalam penelitian ini, pengklasifikasian yang diadopsi adalah skema yang digunakan oleh Guthrie and Petty (2000). Dalam skema ini, IC dikategorikan dalam dalam 3 kelompok: internal structures (organisational capital: 11 item); external structures (customer/relational capital: 9 item); dan employee competence (human capital: 8 item). Berikut adalah detail komponen IC yang digunakan dalam penelitian ini:

a. Internal (structural) capital

1. Intellectual property

2. Patents

3. Copyrights

4. Trademarks

5. Infrastructure assets

6. Management philosophy

7. Corporate culture

8. Management processes

9. Information systems

10. Networking systems

11. Financial relations

b. External (customer/relational) capital

12. Brands

13. Customers

14. Customer loyalty

15. Company names

16. Distribution channels

17. Business collaborations

18. Licensing agreements

19. Favorable contracts

20. Franchising agreements

c. Employee competence (human capital)

21. Know-how

22. Education

23. Vocational qualification

24. Work-related knowledge

25. Work-related competencies

26. Entrepreneurial spirit

27. Reactive ability

28. Changeability

Dari 28 item IC disclosure, terdapat beberapa item yang diungkapkan oleh semua perusahaan, yaitu "sistem jaringan", "hubungan keuangan", "brand", dan "company nama". Sedangkan "patent", "copyright", dan "budaya organisasi" tidak diungkapkan oleh satu perusahaan pun. Gambar 5.1 dan 5.2 mendeskripsikan prosentase pengungkapan IC tahun 2006, 2007 dan 2008 berdasarkan tiga kategori, human capital, customer capital, dan structural capital. 


\section{Analisis \\ Praktik \\ Pengungkapan \\ Informasi...}

\section{2}

\section{Gambar 1}

Persentase

pengungkapan

komponen IC tahun

2006

\section{Gambar 2}

\section{Persentase}

pengungkapan

komponen IC tahun

2007

\section{Gambar 3}

Persentase

pengungkapan

komponen IC tahun

2008
Di tahun 2006, perusahaan mengungkapkan 49\% kategori structural capital, $26 \%$ customer capital dan $25 \%$ human capital (gambar 1 ).

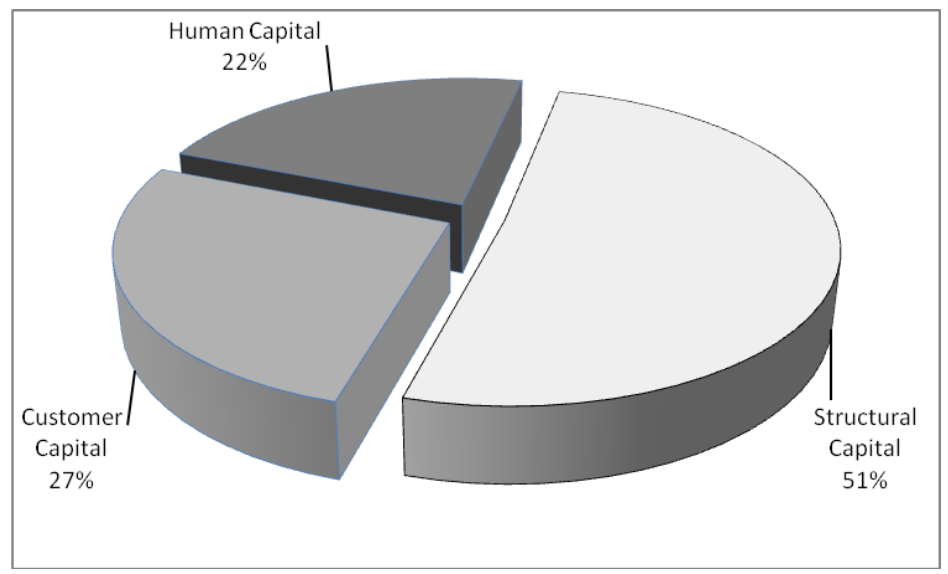

Di tahun 2007, terjadi penurunan prosentase pada kategori structural capital dan peningkatan pada kategori human capital. Sementara kategori customer capital relatif stabil (gambar 2)

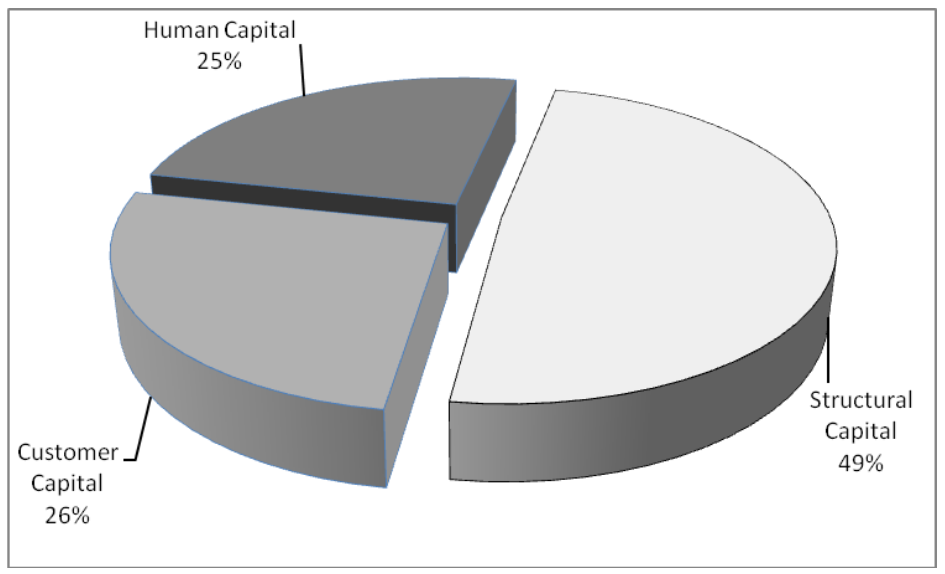

Di tahun 2008 tidak terjadi cukup perubahan prosentase dari tahun sebelumnya (3).

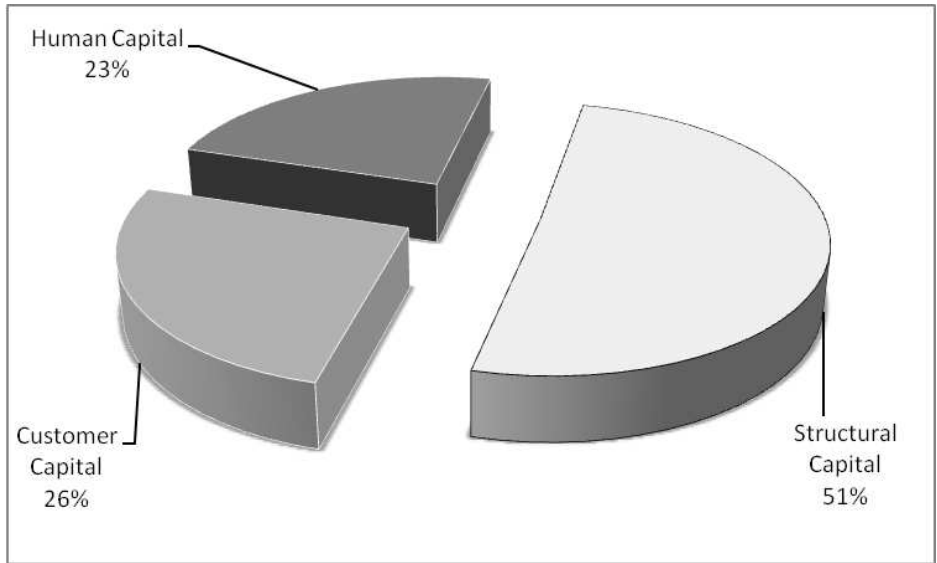

Berikut adalah beberapa contoh pengungkapan atribut IC di dalam laporan tahunan perusahaan publik di Indonesia;

PT. Telkom (2007) tentang trademark:

"Telkomsel menyediakan kepada pelanggannya pilihan layanan prabayar dengan merek dagang "SimPATI" atau layanan pascabayar dengan merek dagang"KartuHALO.” 
"Perseroan memiliki kebijakan internal dan pengembangan budaya perusahaan yang dikenal dengan The TELKOM Way (TTW) 135 ... “.

PT. Excelcomindo Pratama (XL) (2008) tentang management process:

"Melalui komitmen kami yang tinggi dalam menjunjung prinsip-prinsip GCG, kami dapat memaksimalkan imbal hasil, memperbaiki kinerja melalui nilainilai perusahaan kami dan melindungi kepentingan para pemegang saham kami. Kami secara berkesinambungan memperkuat bagan kerja tata kelola perusahaan dalam menghadapi pertumbuhan bisnis yang pesat di tengahtengah lingkungan persaingan bisnis yang amat ketat"

PT. Indosat (2007) tentang entrepreneur spirit:

"Setiap karyawan Indosat dianugerahi beragam potensi serta keunikan talenta tersendiri dalam memberikan kontribusi terhadap pertumbuhan usaha perusahaan. Keberhasilan memadukan kemampuan setiap karyawan menjadi kerjasama yang kuat dan sinergis, telah mempercepat pencapaian pertumbuhan tersebut. Melalui kerjasama dan hubungan yang efektif, kami bekerja erat dengan pemegang saham, mitra usaha, pelanggan, regulator dan institusi terkait lainnya di Indonesia dan Amerika Serikat."

PT. Bakrie Telecom (2007) tentang distribution channel:

"untuk memastikan produk kami tersebar di jaringan toko-toko penjualan produk seluler, kami memperluas jaringan penjualan dan distribusi dengan cara menambah kerjasama distributor, outlet resmi, dan cealer-dealer isi ulang....."

Tabel 1 menggambarkan praktik pengungkapan atribut-atribut IC oleh perusahaan publik di Indonesia tahun 2007 dan 2008. Tabel ini menggambarkan jumlah perusahaan yang mengungkapkan atribut IC secara individual pada setiap tahun.

\section{Analisis Data dan Pembahasan}

Praktek pengungkapan komponen IC dalam laporan tahunan perusahaan telekomunikasi cenderung meningkat dari tahun 2007 ke 2008. Di tahun 2007 misalnya, untuk komponen Internal Capital, hanya $66.7 \%$ (6) atribut yang diungkapkan oleh perusahaan, sementara pada tahun 2008 seluruh atribut telah diungkapkan meskipun tidak oleh semua perusahaan. Atribut 'patent', 'copyright', dan 'trademark' yang ditahun 2007 tidak diungkapkan sama sekali oleh perusahaan, di tahun 2008 muncul di 1 dan 2 laporan tahunan perusahaan.

\begin{tabular}{lcccc}
\hline \multirow{2}{*}{ Intellectual Capital } & \multicolumn{2}{c}{2007} & \multicolumn{2}{c}{2008} \\
\cline { 2 - 5 } & $\mathrm{n}$ & Prosentase & $\mathrm{N}$ & Prosentase \\
\hline Internal (Structural) Capital: & & & 1 & \\
Patent & 0 & 0 & 1 & 16.7 \\
Copyright & 0 & 0 & 2 & 16.7 \\
Trademarks & 0 & 0 & 3 & 33.3 \\
Management philosophy & 5 & 83.3 & 1 & 50 \\
corporate culture & 2 & 33.3 & 3 & 16.7 \\
Management processes & 3 & 50 & 2 & 50 \\
IS (Information System) & 5 & 83.3 & 5 & 33.3 \\
Networking system & 6 & 100 & 6 & 100 \\
Financial relation & 6 & 100 & & \\
\hline
\end{tabular}




\begin{tabular}{|c|c|c|c|c|c|}
\hline & & & & & \\
\hline & & & 007 & & 08 \\
\hline Praktik & Intellectual capital & $\mathrm{n}$ & Prosentase & $\mathrm{N}$ & Prosentase \\
\hline gkapan & External (Customer) capital & & & & \\
\hline Informasi... & Brands & 6 & 100 & 6 & 100 \\
\hline 4 & Customers & 5 & 83.3 & 4 & 66.7 \\
\hline 4 & Customers loyalty & 5 & 83.3 & 3 & 50 \\
\hline & Companies' name & 6 & 100 & 6 & 100 \\
\hline & Distribution channel & 4 & 66.7 & 4 & 66.7 \\
\hline & Business collaboration & 4 & 66.7 & 3 & 50 \\
\hline & Licensing agreement & 6 & 100 & 4 & 66.7 \\
\hline & Favorable contract & 5 & 83.3 & 3 & 50 \\
\hline & Franchising agreement & 2 & 33.3 & 2 & 33.3 \\
\hline & Human Capital & & & & \\
\hline & Know-how & 2 & 33.3 & 3 & 50 \\
\hline & Education & 3 & 50 & 3 & 50 \\
\hline & Vocational qualification & 3 & 50 & 3 & 50 \\
\hline & Work-related knowledge & 5 & 83.3 & 3 & 50 \\
\hline & Work-related competencies & 4 & 66.7 & 2 & 33.3 \\
\hline & Entrepreneur spirit & 2 & 33.3 & 3 & 50 \\
\hline & Innovativeness & 3 & 50 & 3 & 50 \\
\hline & Proactive & 2 & 33.3 & 2 & 33.3 \\
\hline & Reactive Abilities & 3 & 50 & 3 & 50 \\
\hline & Changeability & 3 & 50 & 1 & 16.7 \\
\hline
\end{tabular}

Sumber: data penelitian (diolah, 2010)

Namun demikian, ada pula perusahaan yang 'mengurangi' jumlah pengungkapan atribut IC-nya. Misalnya, atribut 'management philosophy' dan 'information system' yang di tahun 2007 diungkapan oleh 5 perusahaan, pada tahun 2008 hanya diungkapkan oleh 3 dan 2 perusahaan. Demikian pula dengan atribut 'corporate culture' dan 'networking system' yang juga berkurang 1 perusahaan yang mengungkapkannya.

Dalam kategori External (Customer) Capital, semua atribut telah diungkapkan oleh perusahaan, baik pada 2007 maupun 2008. Hanya saja, jumlah perusahaan yang mengungkanpkannya terjadi penurunan. Atribut 'brand' dan 'companies' name' diungkapkan oleh seluruh perusahaan telekomunikasi selama 2 tahun pengamatan. Sementara atribut 'licensing agreement' yang di tahun 2007 diungkapkan oleh seluruh perusahaan, pada 2008 terdapat 2 perusahaan yang tidak mengungkapkannya dalam laporan tahunan.

Atribut lain yang juga turun jumlah perusahaan yang mengungkapkan adalah 'customers', 'customers loyalty', 'business collaboration', dan 'favorable contract. Sementara atribut 'franchising agreement' tidak mengalami perubahan.

Pergeseran pengungkapan atribut IC tampak terjadi juga di komponen $\mathbf{H u}-$ man Capital. Dalam komponen ini pergeserannya cukup banyak didominasi oleh penurunan jumlah perusahaan yang mengungkapkannya. Hanya atribut 'entrepreneur spirit' yang mengalami kenaikan dari 2 perusahaan menjadi 3. Sedangkan atribut-atribut lainnya cenderung turun, misalnya 'know-how', 'Work-related knowledge', 'Work-related competencies', dan 'Changeability'.

Temuan penelitian ini memang tampak lebih 'baik' dari sisi frekuensi pengungkapan jika dibandingkan dengan beberapa penelitian di luar negeri. Hal ini sangat mungkin karena jumlah objek penelitian ini hanya 6 perusahaan (karena perusahaan publik di sektor telekomunikasi di Indonesia juga cuma ada 6), sehingga prosentasenya menjadi tampak lebih besar. Beberapa riset yang telah dilakukan di beberapa negara, frekuensi pengugkapan atribut IC-nya tidak lebih dari 50\% (lihat tabel 2) 


\begin{tabular}{|c|c|c|c|c|}
\hline \multirow[b]{2}{*}{ Peneliti } & \multirow{2}{*}{$\begin{array}{l}\text { Rata-rata jumlah } \\
\text { atribut IC yang } \\
\text { dilaporkan tiap } \\
\text { laporan tahunan }\end{array}$} & \multicolumn{3}{|c|}{ Frekuensi Pengungkapan (\%) } \\
\hline & & $\begin{array}{l}\text { External } \\
\text { Capital } \\
\text { Attributes }\end{array}$ & $\begin{array}{l}\text { Internal } \\
\text { Capital } \\
\text { Attributes }\end{array}$ & $\begin{array}{c}\text { Human } \\
\text { Capital } \\
\text { Attributes }\end{array}$ \\
\hline $\begin{array}{l}\text { Guthrie \& Petty } \\
(2000)\end{array}$ & 8.9 & 40 & 30 & 30 \\
\hline $\begin{array}{l}\text { Abeysekera \& } \\
\text { Guthrie (2000) }\end{array}$ & N/A & 41 & 24 & 35 \\
\hline Brennan (2001) & 3.7 & 49 & 29 & 22 \\
\hline April et al. (2003) & 10.4 & 40 & 30 & 30 \\
\hline Bozzolan et al. (2003) & 51 & 49 & 30 & 21 \\
\hline Goh \& Lim (2004) & 14.6 & 41 & 37 & 22 \\
\hline
\end{tabular}

Sumber: Miller and Whiting, 2005

\section{Simpulan, Keterbatasan dan Saran}

\section{- Simpulan}

Prosentase pengungkapan komponen-komponen IC di dalam laporan tahunan perusahaan telekomunikasi di Indonesia relatif tinggi jika dibandingkan dengan beberapa temuan di negara lain. Pada tahun 2007, masih terdapat beberapa atribut IC yang tidak diungkapkan sama sekali oleh perusahaan telekomunikasi, antara lain 'patent', 'copyright', dan 'trademark'. Di tahun 2008, seluruh atribut IC telah diungkapkan oleh perusahaan, hanya saja tidak semua perusahaan telekomunikasi mengungkapkannya.

Dari 6 perusahaan telekomunikasi yang menjadi objek penelitian ini, tidak satupun perusahaan yang mengungkapkan seluruh atribut IC dalam laporan tahunannya. Maksimal jumlah atribut yang diungkapkan adalah 24 .

\section{- Keterbatasan \& Saran}

Keterbatasan utama penelitian ini adalah terletak pada objek penelitian yang hanya 6 perusahaan di satu sektor industri. Sehingga dengan demikian hasilnya tidak dapat dijadikan ukuran dalam menilai praktek pengungkapan komponen IC oleh perusahaan publik di Indonesia secara keseluruhan.

Oleh karena itu, penelitian selanjutnya disarankan dapat menggunakan objek penelitian yang lebih luas dari jenis industri yang lebih beragam.

\section{Daftar Pustaka}

April, K.A., P. Bosma and D.A. Deglon. 2003. "IC measurement and reporting: establishing a practice in SA mining". Journal of Intellectual Capital. Vol. 4 No. 2. pp. 165-180.

Ariestyowati, E. Suprapti., and I. Ulum. 2009. Analisis pengaruh karakteristik perusahaan terhadap luas pengungkapan informasi intellectual capital pada laporan tahunan perusahaan publik di Indonesia. Paper dipersiapkan untuk simposium nasional akuntansi XII Palembang.

Aprilima PR., I. Ulum, and Susenohaji. 2009. Pengungkapan informasi intellectual capital pada laporan tahunan dan dampaknya terhadap kinerja keuangan perusahaan public di Indonesia. Paper dipersiapkan untuk simposium nasional akuntansi XII Palembang. 
Analisis

Praktik

Pengungkapan

Informasi...

56
Bozzolan, S., F. Favotto, and F. Ricceri. 2003. "Italian annual intellectual capital disclosure; An empirical analysis". Journal of Intellectual Capital. Vol. 4 No. 4. pp. 543-558.

Brennan, N. 2001. "Reporting intellectual capital in annual reports: evidence from Ireland". Accounting, Auditing \& Accountability Journal. Vol. 14 No. 4. pp. 423-436.

Bukh, P.N., H.T. Larsen, and J. Mouritsen. 2001. "Constructing intellectual capital statements”. Scandinavian Journal of Management, Vol. 17 No. 1, pp. 87108.

Campbell, D.J. 2000, "Legitimacy theory or managerial reality construction? Corporate social disclosure in Marks \& Spencer plc corporate reports, 1969-1997". Accounting Forum. Vol. 24. No. 1. pp. 80-100.

Canibano, L., M.G. Ayuso, M.P. Sanchez, and M. Olea. 1999. "Measuring intangibles to understand and improve innovation management. Preliminary results". Paper presented at the International Symposium Measuring and Reporting Intellectual Capital: Experiences, Issues and Prospects. June. Amsterdam.

Chen, M.C., S.J. Cheng, Y. Hwang. 2005. "An empirical investigation of the relationship between intellectual capital and firms' market value and financial performance”. Journal of Intellectual Capital. Vol. 6 N0. 2. pp. 159-176

Goh, P.C., and K.P. Lim. 2004. "Disclosing intellectual capital in company annual reports; Evidence from Malaysia". Journal of Intellectual Capital Vol. 5 No. 3. pp. 500-510.

Guthrie, J., and R. Petty. 2000. "Intellectual capital: Australian annual reporting practices". Journal of Intellectual Capital. Vol. 1 No. 3. pp. 241-251. and F. Ricceri. 2006. "The voluntary reporting of intellectual capital; comparing evidence from Hong Kong and Australia”. Journal of Intellectual Capital. Vol. 7 No. 2. pp. 254-271.

Miles, M.B, A.M. Huberman. 1994. Qualitative Data Analysis, second edition. Sage Publication. New Delhi.

Tan, H.P., D. Plowman, P. Hancock. 2007. "Intellectual capital and financial returns of companies. Journal of Intellectual Capital. Vol. 8 No. 1. pp. 76-95.

Ulum, I. 2008a. Pengaruh intellectual capital terhadap kinerja keuangan perusahaan perbankan di Indonesia. Call for paper Simposium Nasional Akuntansi XI. Ikatan Akuntan Indonesia. Pontianak.

2008b. Intellectual capital and financial return of listed Indonesian banking sector. Proceeding international research seminar and exhibition. Lemlit UMM. Malang.

2009. Intellectual Capita; Konsep dan Kajian Empiris. Graha Ilmu. Yogyakarta

Williams, S.M. 2001. "Is intellectual capital performance and disclosure practices related?". Journal of Intellectual Capital. Vol. 2. No. 3. pp. 192-203. 